\title{
Physical Revitalization of the Eastern Buddha Statue in Bamiyan Using Reinforced Adobe Material
}

\author{
Georgios Toubekis, Michael Jansen, and Matthias Jarke
}

\begin{abstract}
The magnitude of destruction on cultural heritage worldwide creates unprecedented challenges for its rehabilitation since conservation activities must be integrated into the context of larger rehabilitation efforts. It is argued that an authentic remodelling of the Eastern 38 m Buddha establishing the previous spatial configuration of the figure has to integrate the original fragments, combining scientific analysis of the figure's original physical remains with the careful interpretation of the existing documented sources. The authors propose a phased approach using a composite material matrix based on silt-clay close to the original cliff conglomerate embedding also the original fragments. The presented community-based rebuilding intervention executed by local artisans and artists conceptualizes on the evolution of the figurative meaning of the monument over time with the overall objective to use traditional building techniques to retain tangible and intangible values that maintain

\footnotetext{
In Collaboration with,

Technical Advice on Materials: Prof. Dr.-Ing. Michael Raupach, Prof. Dr. rer.nat. Oliver Weichhold, Institute of Building Materials Research, RWTH Aachen University

3D/CAD Drawing: Dipl.-Ing. Irmengard Mayer (Technical University Vienna), Dipl.-Ing. Andreas Walther (v-cube, Aachen)
}

Published jointly by the United Nations Educational, Scientific and Cultural Organization (UNESCO), 7, place de Fontenoy, 75007 Paris, France, the UNESCO Office in Kabul, ICON Compound, Supreme Road, Off Jalalabad Road, PD 9, Kabul, Afghanistan, and Springer Nature Switzerland AG, Gewerbestrasse 1, 6330 Cham, Switzerland.

\author{
G. Toubekis $(\bowtie)$ \\ Information Systems, RWTH Aachen University, Aachen, Germany \\ e-mail: toubekis@dbis.rwth-aachen.de \\ M. Jansen \\ Research Center Indian Ocean, [RIO] Heritage, German University of Technology - GUtech, \\ Muscat, Oman \\ e-mail: michael.jansen@ rio-heritage.org \\ M. Jarke \\ Information Systems, RWTH Aachen University, Aachen, Germany \\ Fraunhofer Institute for Applied Information Technology - FIT, Sankt Augustin, Germany \\ e-mail: jarke@dbis.rwth-aachen.de
}


the authenticity and the specific significance and spirit of this place. The result has the potential to contribute to a necessary reconciliation process. It may serve as an exemplary case in World Heritage context able to bridge different cultural approaches to heritage among regional, national, and international bodies and stakeholders while respecting diverse values, meanings and the Buddha figure's original physical remains alike.

Keywords Word heritage $\cdot$ Authenticity $\cdot$ Reconstruction $\cdot$ Genius loci · Community $\cdot$ Values $\cdot$ Cultural heritage

\section{Overall Approach to Conservation and Presentation of the Property}

The magnitude of disasters and destruction, whether intentional or not, caused by natural disaster or armed conflicts on heritage sites all over the world creates unprecedented challenges for recovery and possible restoration measures. Conservation of cultural heritage in these circumstances must be seen in the context of larger rehabilitation efforts and thus has effects that reach beyond the heritage property itself, especially where communities are directly affected. Recovery from destruction involves here processes and long-term commitments on behalf of responsible authorities, and it is important to engage very early a dialogue process among the involved stakeholders. In landscape contexts, as is the case in Bamiyan, a fundamental requirement is the necessity to reach agreements with local communities and others, which by their decision and activities may have an impact on heritage, and to define a shared vision of the future and identify the means to achieve the envisaged goals (Mitchell et al. 2009). The World Heritage property in Bamiyan comprises eight different heritage areas, all of them with specific characteristics. Besides the main cliff with the empty niches, there are the vast archaeological remains of historic cities and fortresses and other historical cave settlements in the adjunct valleys of Kakrak and Foladi. In order to make the multidimensional values (archaeological, historical, cultural, aesthetic, and economic) better understandable, it is important to develop a communication and mediation strategy, that is able to bring different aspects together into a coherent narrative - also to find ways to bridge different cultural and language approaches to heritage among regional, national, and international bodies and stakeholders involved. Moreover, historic sites are invaluable sources for historical research, as authentic and tangible witnesses of the past that has survived through history. Any conservation strategy, therefore, has to ensure that original materials are well preserved in the long term - if possible in situ or close to their place from where they originate (Schmidt 1997). For Bamiyan, this includes the site of the empty niches, the rock fragments stored in provisional shelters, the original plaster fragments stored in locked storage rooms at the Cultural Hill, and the plaster and sculptured rock surface still in situ. 


\subsection{Options for the Presentation of the Niches of the Bamiyan Buddhas in the Future}

A crucial controversy about the future presentation of the main Buddha cliff turned out to be the key debate, unsolved to date. The arguments are bouncing between two poles: either leaving the site as is, empty niches as a kind of memorial to the destruction, or attempting to rebuild part or all of a figure, a standpoint taken by the Afghan government and backed intensely by the local population - to have at least one figure revived from the ruins as an act of symbolic resurrection. Due to the still required intensive consolidation of the niche rear wall, this cannot be pursued for the Western Buddha for the foreseeable future. The situation at the Eastern Buddha niche is considered more promising by the promoters of the second line of thought.

During workshops in Bamiyan in October 2016 and last in April 2017, it was revealed from participating local villagers to the authors - that there exists a desire of getting re-enchanted with the area - which was once "guarded" by the Bamiyan Buddha figures as the local population sees it. In order to recover the distinctive and unique aspects of the site, we argue with the Spirit of the Place (Genius Loci) that a physical intervention is justified and covered by the International Principles of Conservation. We argue further that it is the appreciation of its own heritage and the strong ties between the local population with its heritage that is to be re-established by giving the population actively the possibility to contribute to construction activities. It is understood and taken note that such an intervention consequently adds a new attraction to Bamiyan that might be exploited by the tourism industry. It is important for the authors to stress here, Diversity of Cultures, understood as the richness of forms of expressions, are not mere commodities or consumer goods that can only be regarded as objects of commercialization. It is the distinctive nature of cultural goods and activities as vehicles of identity, values, and meaning - laying the foundation for a modern inclusive society. The overall challenge for Bamiyan is to embed all this into the current socioeconomic and general political context which is unfortunately in a very fragile situation. The fact that Bamiyan to date is one of the most stable and secure provinces in the country raises enormous challenges such as repatriation of internal and external refugees, allocation of appropriate land resources for development purposes, and provision of livelihood opportunities for a fast-growing population. Moreover in a country which in large parts is confronted with ongoing violence against civilians and military conflict, such reflections on conservation and presentation of a World Heritage property might appear inappropriate not to say unrealistic. Over the entrance to the Kabul museum, an inscription reads "A nation stays alive when its culture survives" to memorize the efforts over the long period of military conflict that the museum as institution managed to overcome. Acknowledging this, the authors of this study are convinced that efforts in the cultural resources of a nation contribute effectively to peacebuilding and achieving long-term development goals.

We, therefore, propose a conservation and presentation strategy based on the following three principal pillars: 
- Preservation of original material with minimal alterations to substance to maintain original source character (Conservation)

- Embedding the presentation of the site into a narrative that presents the richness and significance of its values over time and the contemporary (Mediation)

- Include the presentation to the public of the area Buddha niches into the broader landscape protection framework of a future Archaeological Park Bamiyan (Management)

The ability to understand the value attributed to the heritage artifact depends on the degree to which information sources about this value may be understood as credible or truthful. ${ }^{1}$ The case of Bamiyan Buddhas reveals once again the importance detailed documentation has in heritage conservation and management. Any future presentation strategy of the site where once the Giant Buddha figures stood has to respect the still existing physical remains as the empty niches of today. Since to the present day we know very little with certainty about the ancient history of the site, this accounts also for the visual appearance of the destroyed Buddha figures which are still a matter of scientific investigation.

\subsection{Making Use of Contemporary AR and VR Technologies}

Since Bamiyan will have the opportunity to house a large Cultural Center with museum facilities located on top of Culture Hill in the near future, the authors propose to install an interpretation and mediation section there that is able to explain the history of the Bamiyan site and of its research and documentation over time. The use of contemporary Virtual Reality technologies, which require regular technical maintenance and secured power supply is proposed. Here the full range of factual information on the previous appearance of the site based on the various scientific hypotheses on the possible color schemes of the Buddha figures (Blaensdorf et al. 2009) and the ancient mural paintings (Taniguchi 2013) can be displayed and technically maintained (Fig. 1).

From the balcony of the Cultural Center with distance to the site, where once the Buddha figures stood, the visitor will be enabled to visually overfly the valley of Bamiyan from the future gardens at Culture Hill and to translate this information into real experience once getting close to the site. It is legitimate to suggest that ubiquitous computing devices such as Smart Phones or Head Mounted Displays in the near future will allow for cost-effective Augmented Reality experience directly at the site, but we argue here that it requires a more direct physical experience to allow for a re-enchantment of the site by the people, especially those living there.

\footnotetext{
${ }^{1}$ See Article 80 of the Operational Guidelines to the World Heritage Convention, UNESCO 2016
} 

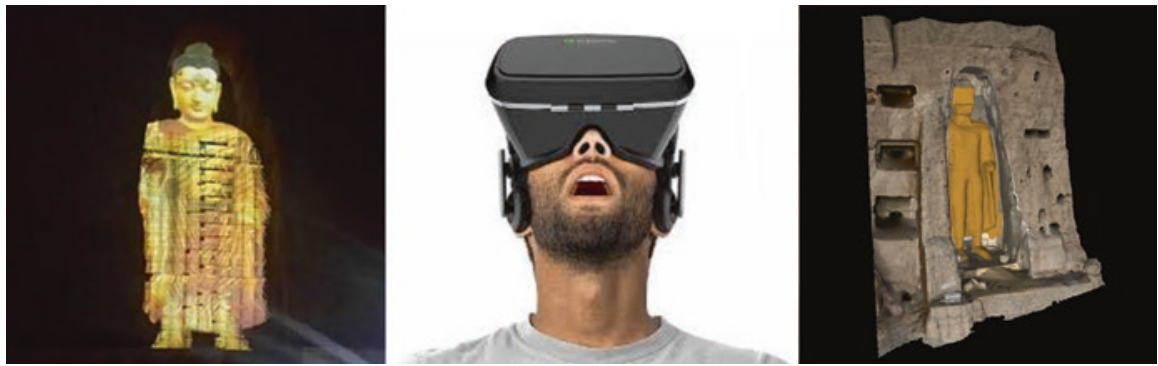

Fig. 1 Examples of VR technologies to display potential appearance of the Bamiyan Buddha in previous times and before its destruction. (Buddha image courtesy of @ zheelaj via Twitter (left) and computer vision image of niche and reconstructed figure by Georgios Toubekis (right), Head Mounted Display by Occulus)
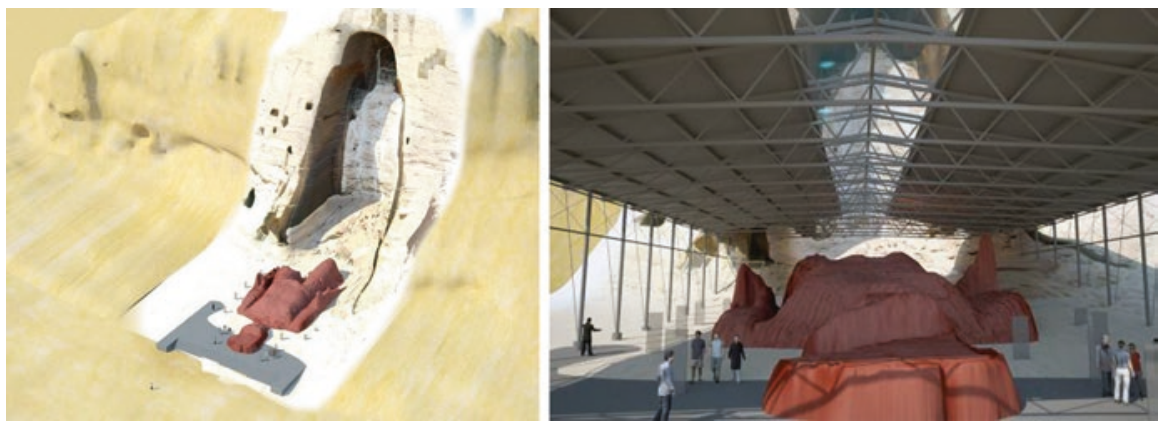

Fig. 2 Presentation of the original rock fragments and sands of the Giant Buddha figure in front of the empty niche. (@ Idea: Michael Jansen, Visualization: v-cube)

\subsection{Preservation and Presentation of the Original Fragments of the Giant 55 m Buddha}

Regarding the situation at the site where once the Western "Large" $55 \mathrm{~m}$ Buddha stood, we propose that the remaining and salvaged fragments shall be laid out in the shape of the original figure in direct vicinity to the niche for long-term storage and safekeeping. The fragments shall be covered by earth and covered with a light roof, allowing view contact with the empty niche. Out of the earth covering the "buried" original material, it is proposed to shape the proportions of the original figure to enable an experience on the size and mass of the original figure (Fig. 2).

\section{Conservation Philosophy Based on OUV of the Property}

The Venice Charter of 1964 considers reconstruction of monuments in the context of restoration establishing the essential elements of significance and the ethical basis for intervention (prevent loss while avoiding damage and deceit) - in light of 
the impact of massive redevelopment of historic city centers after destructions of WW II. The Nara Document of Authenticity underlines that heritage resources can foster processes of appropriation and association within a community including concepts of identity and self-determination based on intensive caretaking of heritage assets (Larsen 1995). As stated in the new ICOMOS Guidance document, ${ }^{2}$ reconstruction is therefore to be considered as part of an overall recovery process from the events of conflict as process itself that responds to particular situations of overall post-conflict strategy as enactor for sustainable development and community well-being - still in relation of the attributes that convey the OUV of the property.

\subsection{OUV of Bamiyan Buddha Niches}

Authenticity, as defined by the Operational Guidelines to the World Heritage Convention, is understood as the undisputed understanding on the credibility of the object's properties. Concepts of authenticity, on the other hand, differ among cultures and as such differ the notion of preserving "authentic" information sources expressed through a variety of attributes; original or genuine material substance (even incomplete), the complete coherence of the original shape, or preserving the locational setting. According heritage practice, in the context of World Heritage, reconstruction is accepted when supportive of the OUV, in cases where reconstructions on the basis of detailed evidence are seen to give meaning to the designated landscape or where intensive restoration and reconstruction is considered as a means of having an idealized image that could forge a national identity. Reconstruction has also been accepted in relation to sustaining the explicit or implicit attributes of OUV, not only in relation to fabric but also to processes, uses, and associations and in properties where the replacement of fabric responds to deterioration (ICOMOS 2017). With reference to the various recommendations of the Bamiyan Working Expert Group since 2002, partial reconstruction of the Giant Buddha figures has been always reiterated as appropriate conservation strategy once the required consolidation of the rock surface is completed. Any classic restoration activity therefore firstly has to check, if form, as well as function and physical fabric based on detailed evidence, are not harmed by future interventions and in case of World Heritage that all the measures are executed in such a way; the results must be reversible also in later generations to come. Decision-makers have to keep in mind that any conservation approach has to maintain the authenticity of the property and therefore to be cross-checked against the following tangible and intangible factors (Table 1).

\footnotetext{
${ }^{2}$ ICOMOS has published in 2017; its ICOMOS Guidance on Post trauma recovery and reconstruction for World Heritage Cultural Properties prepared in response to the request for guidance on reconstruction expressed in the World Heritage Committee decision (Decision 40 COM7) at its 40th session in Istanbul, Turkey.
} 
Table 1 Factors that affect OUV of the site, adapted from (ICOMOS 2017)

\begin{tabular}{l|l}
\hline Tangible factors & Intangible factors \\
\hline Materials and substance & Location and setting \\
\hline Form and design & Spirit and feeling - beliefs and rituals \\
\hline Use and function & Techniques and traditions of maintenance \\
\hline
\end{tabular}

With respect to the non-material aspects from the perspective of the local population and the people of Afghanistan, the site where once the Giant Buddha figures stood mark the location of a specific Spirit of the Place that constitute the Authenticity of the Word Heritage of Bamiyan.

Recognizing the intangible component of this specific historic place acknowledges the interaction of traditional beliefs and tales and the way of living of the local population. In order to maintain this and to avoid any harm, it is regarded essential to actively involve the local population in the entire process of any future intervention from the beginning and to share responsibilities in planning and execution. This will require that newly shaped figural parts are created and shaped by people from Bamiyan to truly familiarize with this project and thus maintain authenticity of the existing and as well as newly created components of the monument.

An approach of multidisciplinary national and international expertise together with active collaboration from the people of Bamiyan will provide a richer, more dynamic, and inclusive vision of the cultural heritage of Bamiyan. This will lively demonstrate that the spirit of place can vary in time and from one culture to another according to practices of memory and that a place can have several spirits and be shared by different groups fully in the deeper sense of the World Heritage convention.

\subsection{Assessment of the State of Conservation of the Eastern Buddha Niche}

The niche of the Eastern Buddha and its rear wall has been consolidated successfully within the UNESCO safeguarding program (Petzet 2009, Margottini 2014a, Emmerling and Petzet 2016). However, due to the character of the conglomerate rock material, it must be expected that superficial erosion will continue, and there is always the considerable danger that larger rock blocks detach from the upper cliff parts due to the natural erosion process that cannot be stopped. To address this, a protective canopy for visitors to the rearward caves in the eastern niche, preventing from fall of small stone pieces, was proposed by the restoration team of the Technical University of Munich and led to the construction of two reinforced concrete "pillars" exactly on the location where once the "feet" of the original $38 \mathrm{~m}$ Buddha stood. A supporting beam construction between the two "feet pillars" remained unfinished as well, and the concrete reinforcement steels are laying in the wooden casing (Fig. 6a). These "feet pillars," their construction, and alleged function are described in detail in the ICOMOS evaluation report (ICOMOS 2016). The 

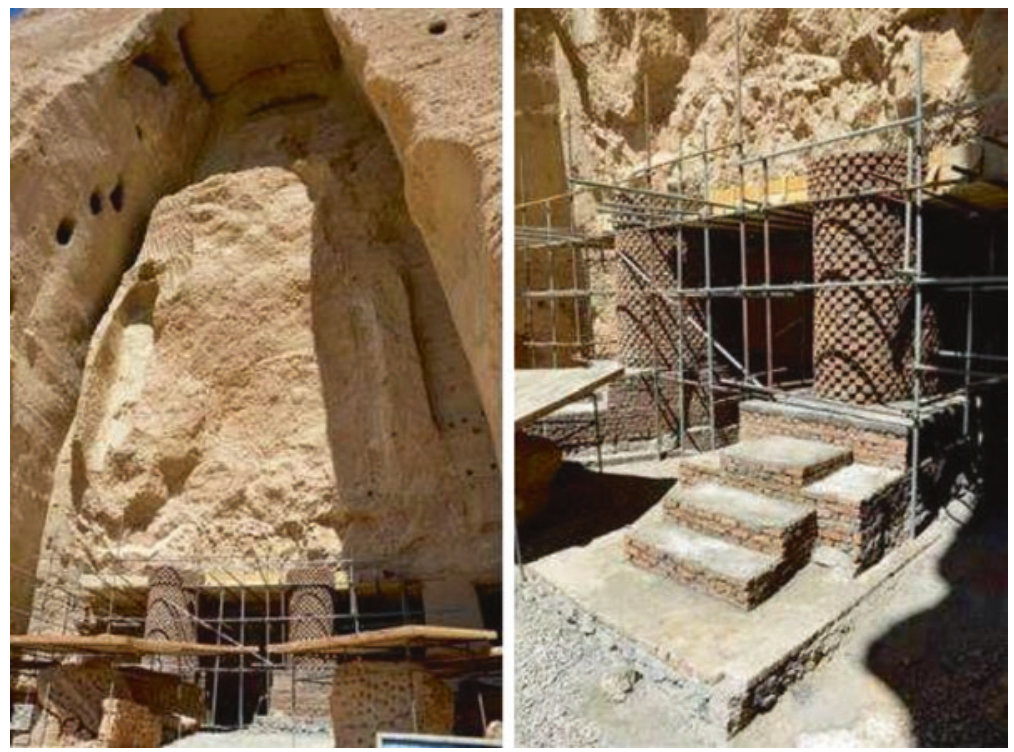

Fig. 3 Situation at the niche of the Eastern "Small" 38 m Buddha as of December 2013, pillars made of reinforced concrete constructed by restoration team of Technical University of Munich. (@ UNESCO)

construction of the "feet pillars" as attested by the ICOMOS evaluation mission imposes a great intervention as efficiency for the alleged purpose is heavily criticized and its unfinished character differs in form and appearance significantly from the carefully restored rear wall (Fig. 3).

When finished their appearance would be likely to follow the example of the previously reconstructed primatic pillar on the eastern side of the rear wall. This prismatic pillar was created to add additional strength to the rear wall at the eastern corner (Fig. 4a-b).

This prismatic pillar deviates significantly from the historically documented pillar shape. Its form does not follow the dimensions and proportions of the previous form (possibly resulting from the extensive restoration campaign of ASI in the 1970s) and shall be build back in the context of any future activity at the site (Fig. 5).

At the bottom of the niche, there are several very large fragments that due to their very delicate state of conservation remained in the niche under individually constructed canopies. During a site visit in October 2016 and April 2017, it could be observed that a larger rock block had detached and fallen from atop the higher parts of the cliff right on the access path in front of the niche. In some vicinity to the $38 \mathrm{~m}$ Buddha niche, the rock fragments documented during the salvage operations in 2005-2007 are still being stored in the temporary shelter next to the entrance gate of the mud wall that encircles the area of the $38 \mathrm{~m}$ Buddha niche (Fig. 6). 
a

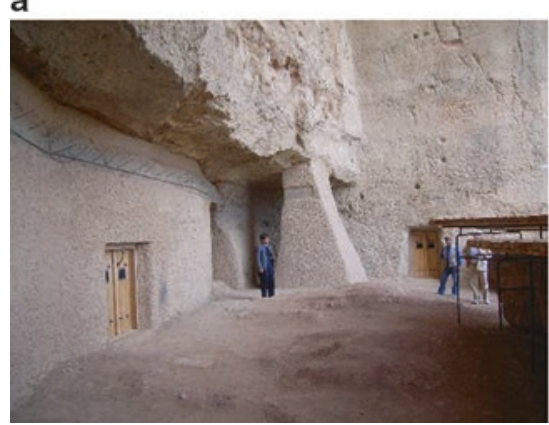

b

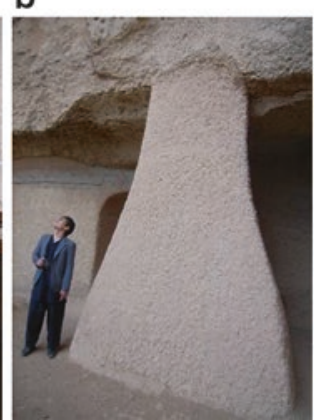

C

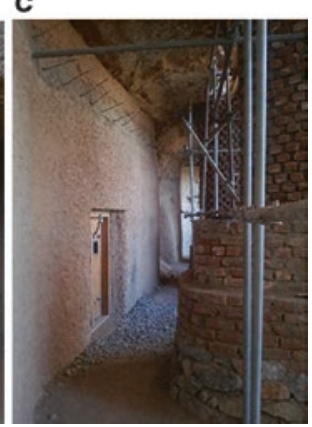

Fig. 4 (a-b) Bottom of the $38 \mathrm{~m}$ Buddha niche in 2012 after finalization of conservation works at the rear wall with prismatic shape of a reconstructed pillar (c) Situation after November 2013 with newly created reinforced concrete "pillar feet". (@ G. Toubekis)

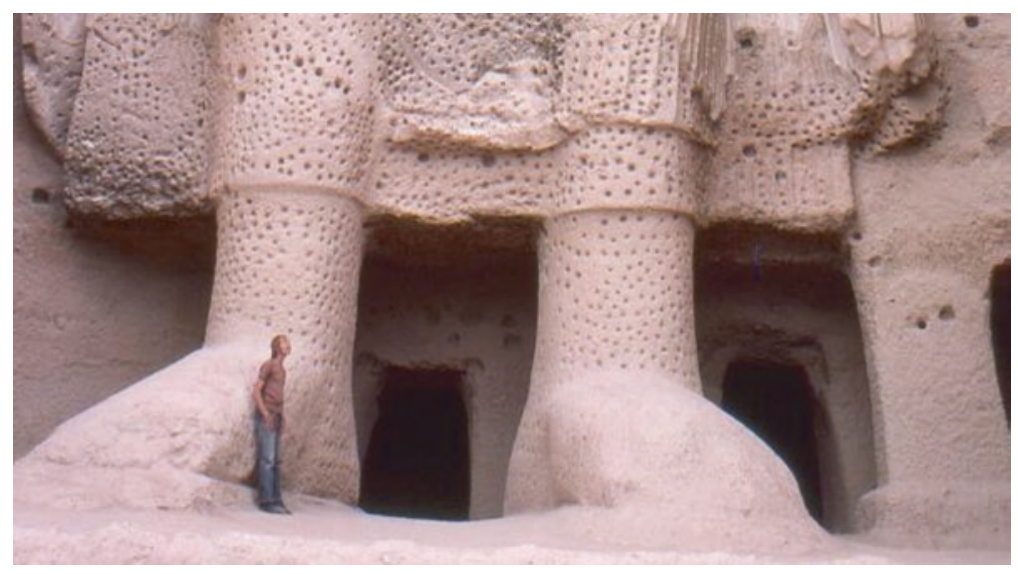

Fig. 5 Situation at the bottom of the $38 \mathrm{~m}$ Buddha niche after completion of the India restoration work in 1974 (note the form of the original pillar to the right). (@) Wikimedia Commons, Public Domain)

A total of 422 individual fragments (see Table 2) showing traces of original surface from the $38 \mathrm{~m}$ Buddha figure could be recovered during the safeguarding campaign, featuring different lithological compositions and varying dimensions of $30 \mathrm{~cm}$ up to $180 \mathrm{~cm}$ in diameter (Toubekis 2008). Altogether these fragments make around $65 \mathrm{~m}^{2}$ of recovered surface material, ${ }^{3}$ roughly $12 \%$ of the ca. $550 \mathrm{~m}^{2}$ total

\footnotetext{
${ }^{3}$ From the historical documentation (Higuchi 1984, pp. 99-100 Vol. 4), a 3D digital model of the $38 \mathrm{~m}$ Buddha could be generated (Toubekis et al. 2011) and serves as basis for the surface calculation.
} 


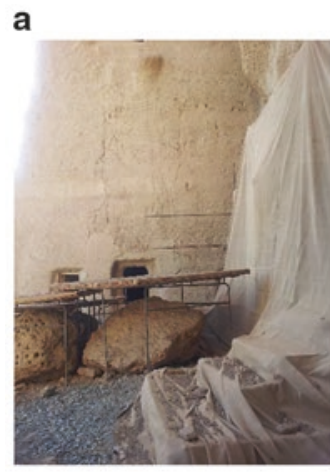

b

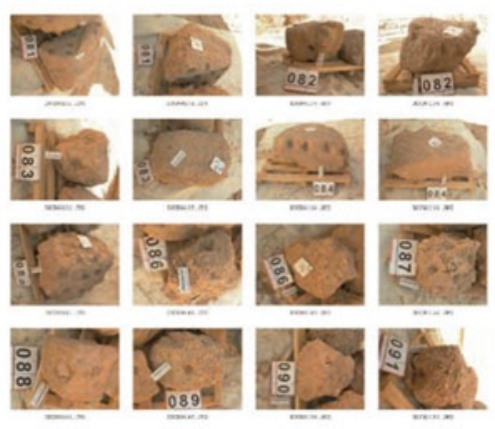

Fig. 6 (a-b) Situation at the bottom of the $38 \mathrm{~m}$ Buddha niche in April 2017 (a) very large fragments located in the niche covered by wood shelters (b) example of smaller stone fragments stored in some vicinity under protective shelters. (C) G.Toubekis)

Table 2 Distribution of safeguarded fragments from the Eastern Buddha niche according to weight classes (approximation)

\begin{tabular}{l|l|l|l|l|l|l|l|l}
\hline $\begin{array}{l}\text { Weight } \\
\text { class }\end{array}$ & $<55 \mathrm{~kg}$ & $<110 \mathrm{~kg}$ & $<385 \mathrm{~kg}$ & $<495 \mathrm{~kg}$ & $0,5 \mathrm{t}<2 \mathrm{t}$ & $3 \mathrm{t}<8 \mathrm{t}$ & $10 \mathrm{t}<22 \mathrm{t}$ & $\begin{array}{l}\text { Total } \\
\text { fragments }\end{array}$ \\
\hline $\begin{array}{l}\text { Pieces of } \\
\text { fragments }\end{array}$ & 137 & 100 & 116 & 17 & 39 & 8 & 5 & 422 \\
\hline$\%$ & 32,4 & 23,7 & 27,5 & 4 & 9,2 & 1,9 & 1,2 & 100 \\
\hline
\end{tabular}

envelope surface ${ }^{4}$ of the digitally reconstructed 3D model of the $38 \mathrm{~m}$ Buddha (Toubekis et al. 2017). The values for the total volume stay in the same range $(\sim 11 \%)$, much less of the assumed remains of $40-45 \%$ that was claimed so far (ICOMOS, 2016, p. 239).

According to the restorers, the recovered surface material at the site of the Western $53 \mathrm{~m}$ Buddha might reach higher rates, but here, precise figures are not yet determined. It must be clearly stated that at least for the site of the $38 \mathrm{~m}$ Buddha niche, the remaining original rock material altogether constitutes only a very small fraction of the previous total surface/volume of the destroyed figure. The absence of this vast amount of original material and the yet unsolved matter of its structural stability mark the challenges that any intervention at the site has to address in the future.

\footnotetext{
${ }^{4}$ Surface area calculations for the salvaged fragments originate from field notes of the collected fragments and from digital measurements of the niche (Jansen et al. 2008).
} 


\section{Concept for the Restoration and Reassembly of the Destroyed $38 \mathrm{~m}$ Buddha Figure}

A sustainable approach to technical conservation on the field implies that the materials and the techniques used for the preservation of the site are, as far as possible, produced in the region and that local building traditions are integrated into the overall approach to conservation and restoration. Consequently, mostly traditional and/ or local materials should be used for the restoration and conservation of the project. We intend to re-establish the contours and the main shape of the figure but refrain from a complete reconstruction of the shape as before the destruction of 2001 or a complete reconstruction of a previous (unknown) appearance. The principal aim is the restitution of the contours of the existing remains without additional stress onto the still existing original plaster material (Fig. 8).

Although the rear wall has been carefully restored and all visible cracks sealed, a superficial erosion is ongoing through loss of surface particles (except for the remaining mud plaster parts) as the conglomerate rock material is exposed to the environment. Here the figural remains can be described as kind of carved stone relief that show similar superficial decay characteristics known from weathering of earthen architecture - however significantly slowed down in time.

The overall conservation strategy, therefore, is proposed to add material in front of the rear wall to restore the outline and to make contours of the destroyed figures readable again and finally to ensure a resurfacing/plastering to protect it from superficial erosion.

While preserving the original outline of the figure where it still exists, it is proposed to do the rebuilding with traditional mud/adobe material to reconstruct the figural elements of legs and the main trunk of the body shape. The newly added material follows the concept of "sacrificial layers" known in the conservation of earthen architecture - where newly added elements should always be "weaker" and "less resistant" to the original ones.

Based on the identification and analysis of historic plaster material and the identification of suitable mud resources in the valley of Bamiyan, new improved mud mortars and mixtures are proposed for the form of the legs/body and surface plaster. Attention to material continuity and affinity is essential as well as technological and static compatibility between old and restored elements. Since the original static system consisted basically of the adherence of the Buddha's figure rock material with the conglomerate mass of the cliff, a new static system is required for building up the proposed earth masses. For this reason, the rebuilding will concentrate on legs and the main trunk of the body shape, where forces can be directed vertically down into the bottom of the niche. We abstain from reconstructing overhanging figure parts in order to avoid cantilever moments resulting from far outreaching parts of the garment or forearms of the original figure. In order to achieve an acceptance of the local population to the overall result, we propose that the main figural elements of the shape of the Buddha (legs/trunk/shoulder) shall be erected 

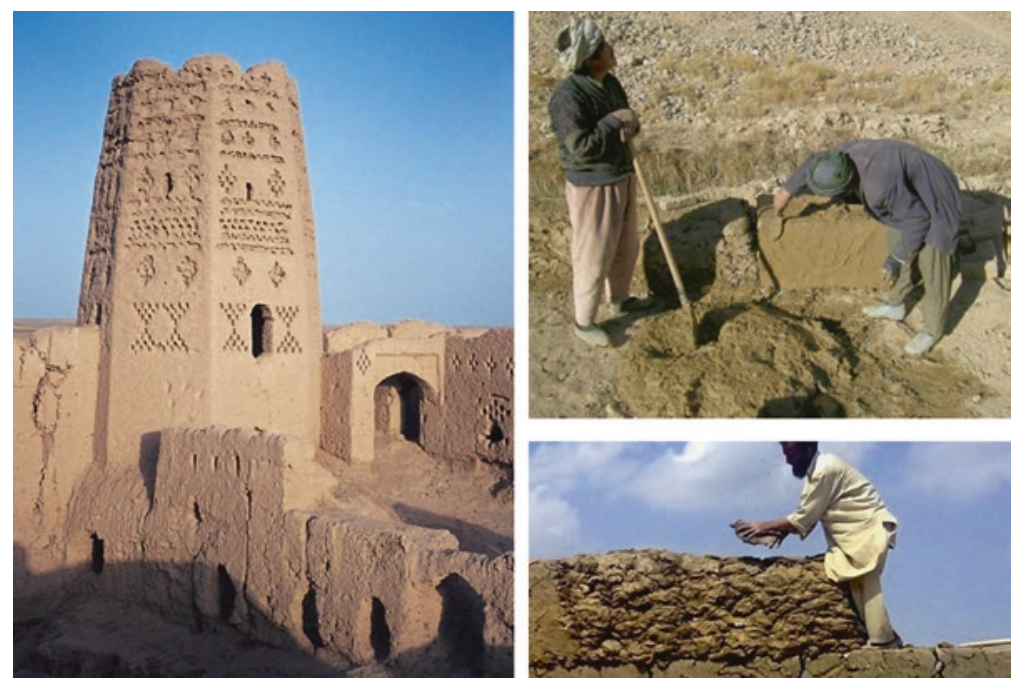

Fig. 7 (Left) Traditional "Qala" house in Afghanistan with octagonal tower, decorations carved into the soft wall during construction. (Right) Construction process of a traditional "pachsa" cob wall in line segments with finish of fine "kaghel" plaster. (@ P. Smars/RWTHacdc)

following the traditional wall erection method with rammed earth called locally "pachsa" using mud material available in the region (Fig. 7).

The active involvement of the local community into the reconstruction process is considered essential to achieve the alleged psychological "healing" effect. To erect and shape the reconstructed $38 \mathrm{~m}$ Buddha "From people from Bamiyan, for the people of Afghanistan and the rest of the World as a symbol of Peace" is considered the baseline narrative which shall constitute to the authenticity of the final result building upon the historical, religious, and symbolic values so far.

\section{Technical Details of the Revitalization Proposal}

The area of the Bamiyan cliff is located in a semi-arid environment of the mountainous central highlands of Afghanistan with an extreme climate with very cold winters and hot and dry summers (mean $7.5^{\circ}$ ) with little mean annual precipitation of around $160 \mathrm{~mm}$. The general geology of Bamiyan is described by (Lang 1968, 1972) as an intra-mountainous basin covered with debris from the surrounding mountain ranges. The central Afghanistan tectonic setting is extremely complex with extremely faulted mountain ranges and high seismic activity. The Bamiyan Valley is located within the Herat fault which is an extension of the overall Indian Ocean Owen transform fault system. The diverse mountain ranges of the Hindu Kush slowly slide along this mountain range leading repeatedly earthquakes of high magnitude as recorded evidence has shown (Bourrouilh-Le Jan et al. 2007). Geomorphological 
and geophysical properties of the Bamiyan cliff have been described in various reports during the UNESCO/JFIT campaign.

An environmental assessment (Reinecke 2005) has been elaborated by the RWTH Aachen Center for Documentation and Conservation (RWTHacdc) during the elaboration of the Cultural Master Plan for the Bamiyan Valley, and the general environmental condition and morphological evolution of the central Bamiyan cliff are described by (Delmonaco and Margottini 2014).

The mineralogical and petrological graphical composition the cliff material has been investigated by (Fecker 2009; Margottini 2014b). The material from which once Giant Buddha figure where carved out of the cliff is composed out of sediments of varying grain size up to $20 \mathrm{~cm}$ interbedded with matrix-supported silt and sand and extremely vulnerable to the exposition of water. Various tests have determined technical parameters of the cliff parameters such as natural density of around $\rho=2.00-2.28 \mathrm{~g} / \mathrm{cm}^{3}$ for the siltstone and the conglomerate matrix with individual solid components within the matrix reaching values up to $\rho=2.62 \mathrm{~g} / \mathrm{cm}^{3}$. Unaxial compressive strength is given with $2.99 \mathrm{MPa}$ for the conglomerate and between 6.73 MPa and 6.91 MPa for the siltstone material.

Bamiyan is located in a region with high seismic activity with reported earthquakes of a magnitude of $M>7$ in recent times (Ambraseys and Bilham 2014); therefore a ground acceleration of 1.6 to $2.4 \mathrm{~m} / \mathrm{s}^{2}$ due to earthquakes must be taken into consideration when considering large-scale constructions as the site of the Bamiyan Buddhas (Fecker 2009, p. 106).

About the original construction procedure, only some hypothesis exist (Tarzi 1977); however from the practical knowledge, it can be assumed that the plastering was directly done after carving the figure from the cliff with the help of some scaffold construction. The original $38 \mathrm{~m}$ figure was carved out of the original conglomerate stone in a kind of extended relief technique where the sculpted elements remained attached to the solid background cliff material and where afterward plastered with different grained mud plasters. Of this plaster, some portions still exist in situ (green color in damage assessment map in Fig. 9, red color indicate most delicate rock portions requiring intense rock-engineering treatment). The raw-carved cliff was then covered with a mud plaster on which the finer-grained finish plaster was added prior coloring the surface (see Fig. 10 concept sketch). During the restoration of the rear wall, high attention was given to stabilize these portions, and any future treatment has to respect the original fabric of this original material (Fig. 8).

Any proposal for reconstructing the shape of the original figure would require a structural basis for transferring the vertical loads into the ground. We suggest therefore to integrate the existing two pillars, the so-called "feet" at the bottom of the niche into the design proposal. Although their removal has been proposed by the ICOMOS expert mission to Bamiyan assessing their impact on the OUV, we argue that removal would produce intensive vibrations onto the cliff with unpredictable effects on the overall conglomerate material in the vicinity and the stability of the restoration or the rear wall. Keeping this pillar on the other hand also frames the options for an overall load capacity of the proposed supers-structure on top of it. The technical details of these pillars are briefly summarized in the (Emmerling and 


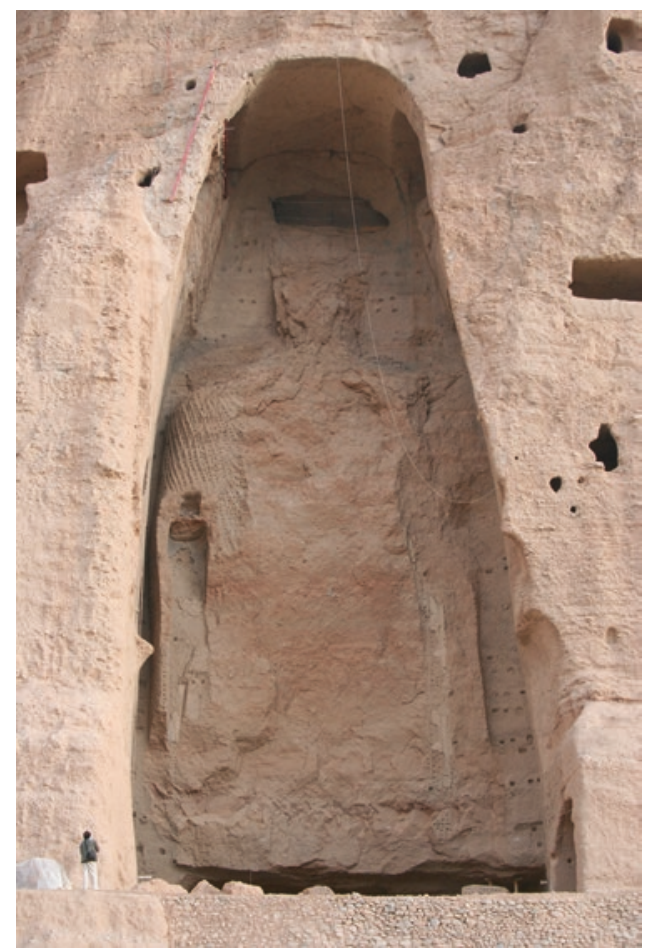

Fig. 8 The rear wall of the Eastern Buddha niche as of 2006 with the remains of carvings and original plaster of the $38 \mathrm{~m}$ Buddha figure. (@ I.Mayer/RWTHacdc)

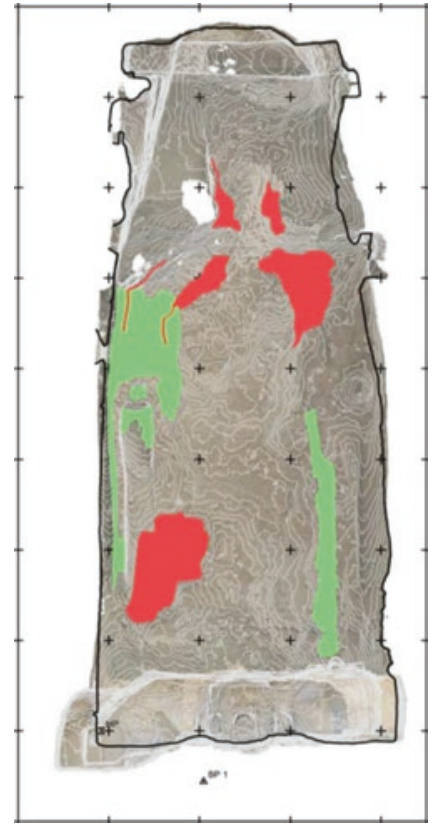

Fig. 9 Damage mapping of rear wall of niche of the Eastern Buddha prior restoration. (C) I. Mayer/A.Thieme/G.Toubekis/RWTHacdc) 


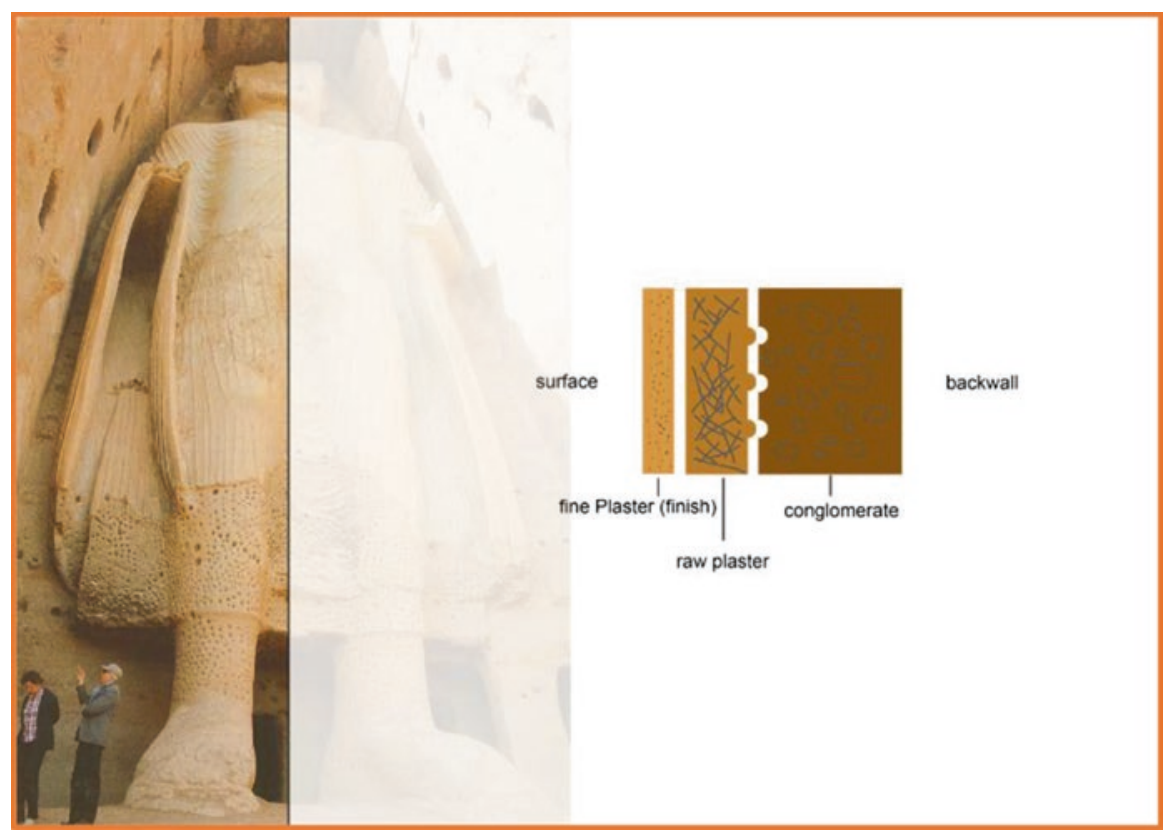

Fig. 10 Schematic structure of materials of the $38 \mathrm{~m}$ Buddha figure. (@ M. Urbat/RWTHacdc)

Petzet 2016). They are positioned at the location which can be extracted from the documentation that has been elaborated by Kyoto University (Higuchi 1984, pp. 99-100 Vol. 4) and has been verified by the Munich team on the ground, tracing the contours of the rock surface. The ground below has been investigated for possible hollow spaces by simple core drillings down to a depth of around $6 \mathrm{~m}$ without cutting any void in the ground and is thus found suitable to accept the loads directed through the pillars. They are realized in reinforced concrete with a load-bearing capacity of $250 \mathrm{t}^{\text {each. }}{ }^{5}$

The solution we propose will consist of a buildup mass of adobe/mud following the previous main figural shape of the $38 \mathrm{~m}$ figure. For this purpose, a horizontal support beam is proposed to be installed on top of the pillar constructions following the shape of the lower edge of the original figure. This beam is envisaged to collect all vertical loads and direct them into the ground through the existing pillars. These pillars would then be classed with cement enhanced mud to form the shape of feet (see Fig. 11). A similar material was used by the Indian restorers of ASI in the 1970s during the rehabilitation of caves structures. For the prismatic pillar at the eastern corner of the niche, it is proposed to build it back/cut it back to its previous dimensions, undoing the prismatic shape and reconstructing the vertical/cubic pillar

\footnotetext{
${ }^{5}$ Personal communication with Prof. Edwin Fecker, supervising engineer during construction on the site in 2013.
} 


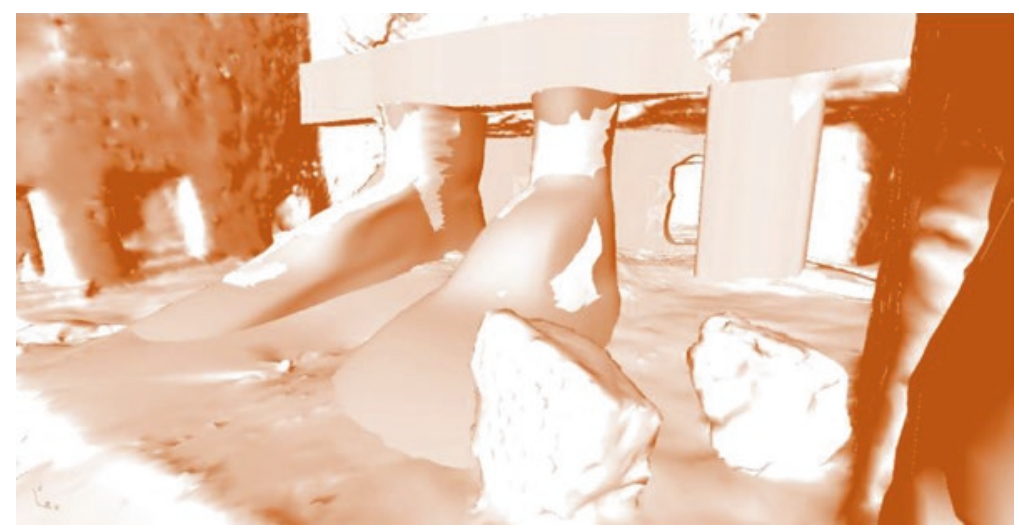

Fig. 11 Proposed newly built concrete slab in between newly built concrete pillars that are to be shaped in previous "feet" form. (@ G. Toubekis/T. Frank)

construction, also in order to free some space for the traditional pradakshina-pātha, the circumambulation passage around the Buddha's feet. The support beam will be designed from data of the digital shape model of the $38 \mathrm{~m}$ Buddha. It will be formed out of reinforced concrete of around $1 \mathrm{~m}$ thickness with a matrix of grains and sands originating from the Buddha cliff. The outline of this slab will follow the lower edge of the previous $38 \mathrm{~m}$ Buddha figure. It will directly connect with the rear wall of the Buddha niche and will be designed to carry the buildup mass of adobe material which is to follow in the next phase. The color of this beam is to be adjusted carefully to the tones of the cliff in the back, following the examples of the Indian restorers of ASI.

Further on we propose the usage of adobe material for building up the Buddha figure which is a material in daily use as a construction material in the region. The process of erection would follow the traditional wall construction procedure by applying line by line of the material of around $50-75 \mathrm{~cm}$ height. The precise outline of the figure shall be then carved out of this block mass by artist sculptors and stonemasons from Afghanistan, thus making it an authentic piece of artwork.

Mud has been used as raw and finish plaster on the figures in previous times, and it originates from the Cultural Landscape. Thus it can be considered an authentic material, with respect to the OUV of the property.

\subsection{Repositioning of Fragments Based on Geological and Paleomagnetic Patterns}

Since both Buddha figures had been originally hewn out of a conglomerate rock surface with a specific sedimentological structure, a paleo- and rock-magnetic methodology is suitable to aid in the relocation of fragments of the giant Buddha 
figures. Correlation of lithological details from the rear side of the Buddha niches to those of the blasted rock fragments has been tested to determine the relative position of the fragments toward the rear side of the niche. Magnetic susceptibility (i.e., the ratio of the magnetization in the rock fabric to the corresponding magnetizing force) was measured, and susceptibility profiles at a spacing of about $5-10 \mathrm{~cm}$ were determined perpendicular to the bedding of the rear niche wall (Fig. 12). The combination of the rock magnetic and geologic methodology is capable of identifying the original position of fragments of the destroyed Giant Buddha figures and has elsewhere been successfully tested in the field for fragments larger than $1 \mathrm{~m}$ (Urbat 2009).

Based on sample tests, the Technical University of Munich has proposed a total impregnation of the salvaged fragments with silicate ester to enhance their physical strength and possible reuse for reconstruction purposes in the future. This option would require the shipment of those fragments out of Afghanistan for treatment in a specialized laboratory and thus seems out of reach for the foreseeable future. We, therefore, propose that individual selected salvaged rock fragments shall be embedded within the mud/pachsa matrix in order to be stored permanently close to the place from where they originate.

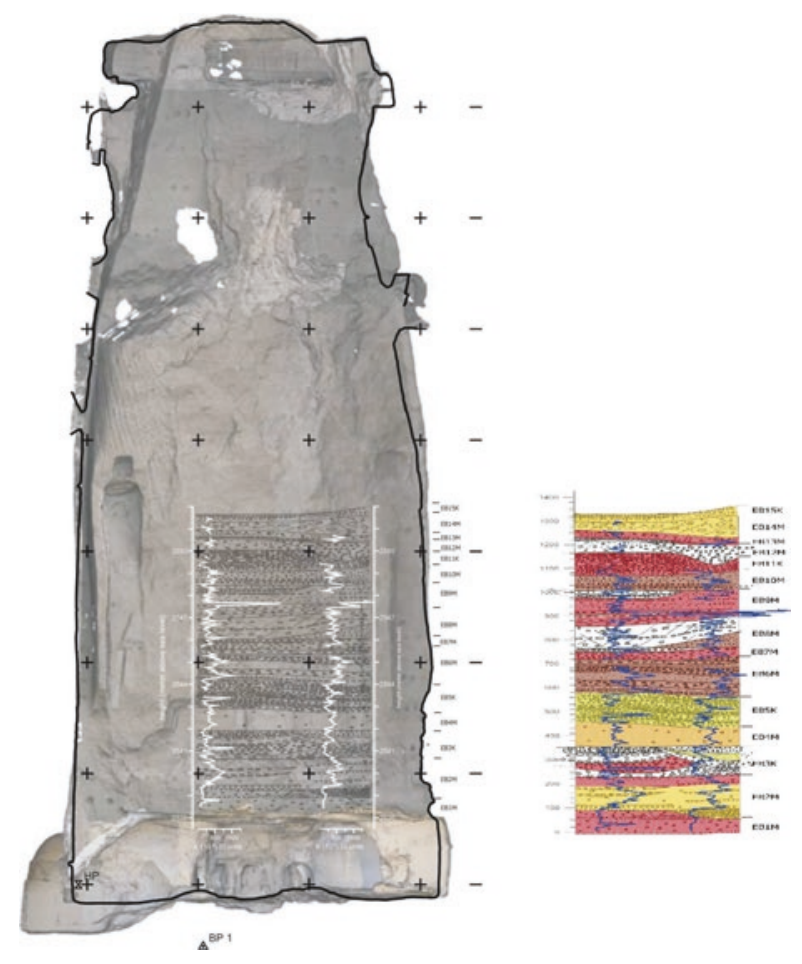

Fig. 12 Rear wall of the $38 \mathrm{~m}$ Buddha niche with geological mapping of stratigraphic units. (C) M. Urbat/RWTHacdc) 


\subsection{Conceptual Sketch of the Reconstruction Process and Operational Implementation Issues}

In 2017, the first author prepared a conceptual sketch for the reconstruction process of the $38 \mathrm{~m}$ Buddha Figure which is reproduced in Figs. 13-15. We propose to realize the reconstruction process in four phases - this would allow to clearly structure the process and adapt the time frame when considered appropriate. Following an initial intensive study phase for consolidation of the scientific basis, we propose a phasing of the project as follows:
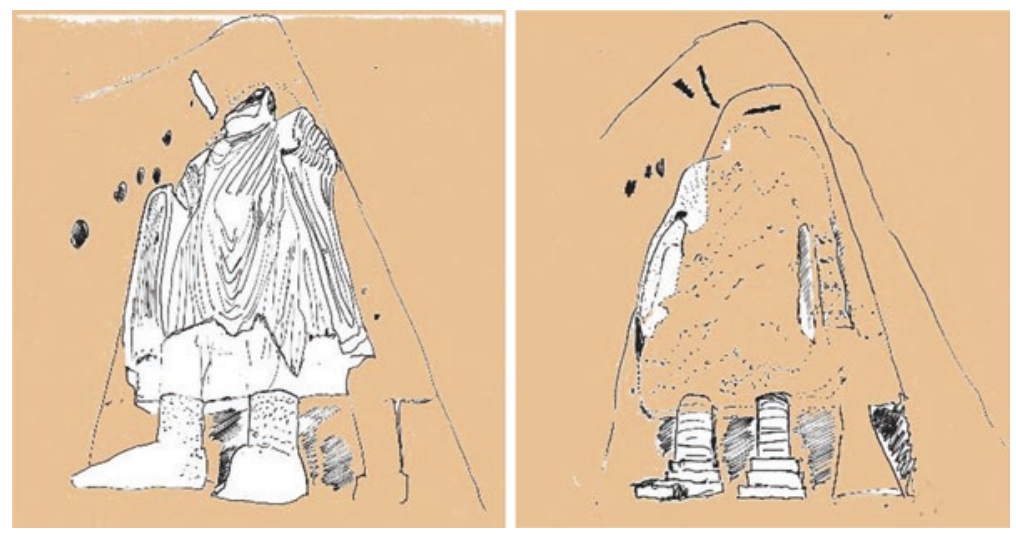

Fig. 13 (Left) Original shape of the $38 \mathrm{~m}$ Buddha before destruction (Right) Situation in the niche as of 2017. (@ G. Toubekis)
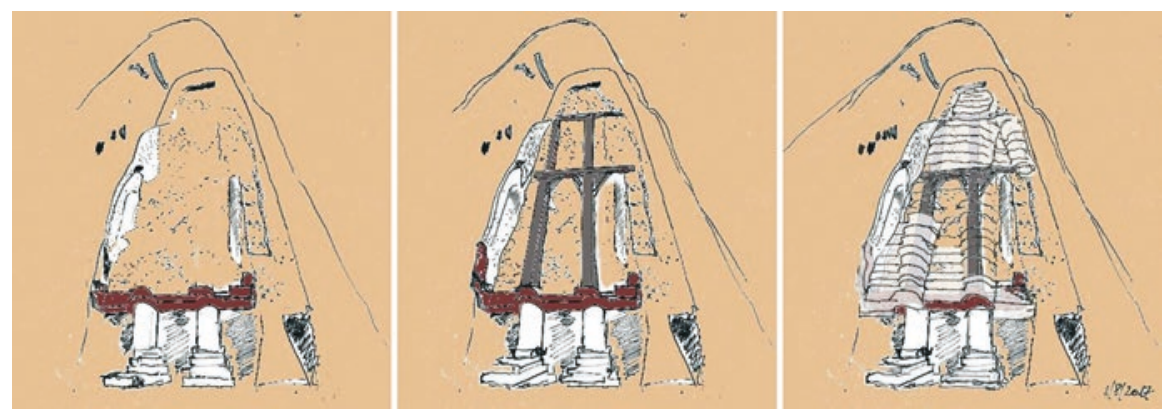

Fig. 14 (a) Phase One. (b) Phase Two. (c) Phase Three-Four. (@ G. Toubekis) 

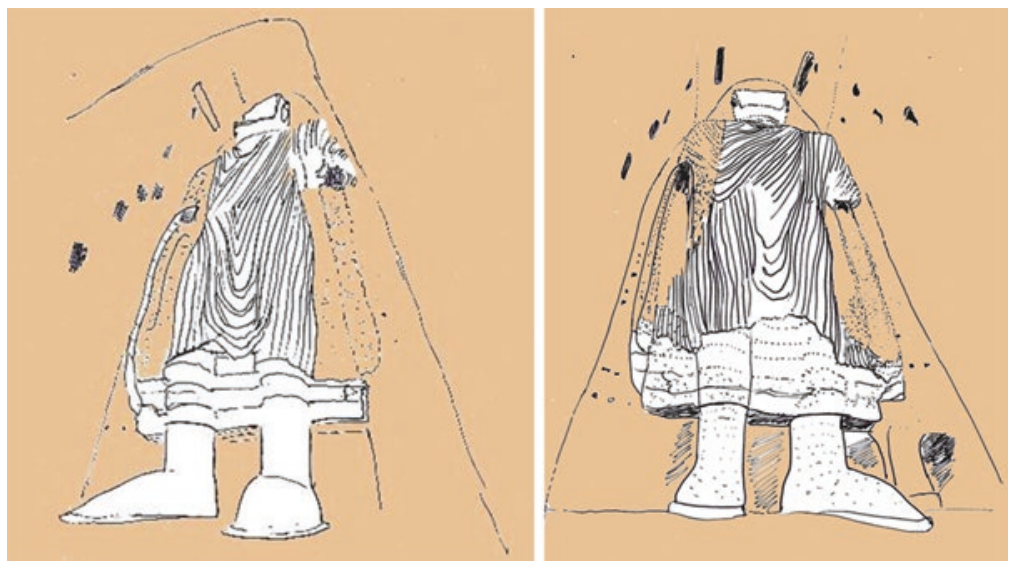

Fig. 15 Phase Five - proposed reconstructed shape of the $38 \mathrm{~m}$ Buddha. ( $\odot$ G. Toubekis)

Table 3 Activity plan and time frame of the project proposal

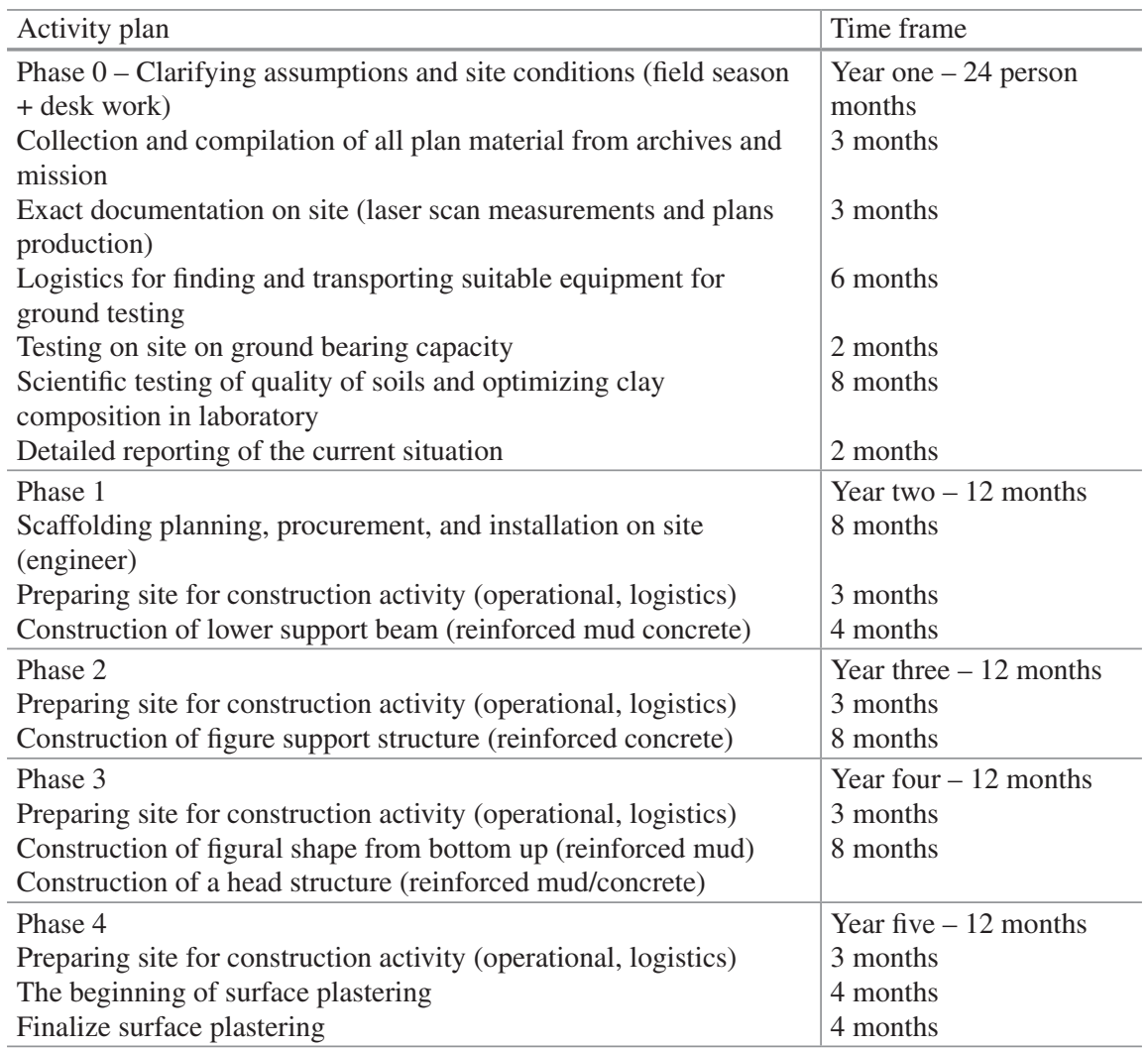




\section{Summary}

The question of reconstruction of destroyed heritage places has a complex impact on post-conflict recovery processes within an affected country. The motivation to pursue a partial or complete reconstruction of at least one of the destroyed Buddha figures is very strongly felt in the Valley and put forward by a local community marginalized in history due to nationwide ethnic and religious differences. It can be interpreted as an incubator for a convalesced self-esteem or simply as a promoter for tourism into this region which to date has been spared from the hostile and violent conflict going on elsewhere in the country. The request of the Venice Charter to hand these places over to future generation "in the full richness of their authenticity" has long been associated with the physical materiality of the place until the Nara document has introduced a broader notion of authenticity to heritage practice worldwide. The case of Bamiyan appeals urgently that debate about reconstructing heritage places misses a key point when it is merely focused on the matter of material design and available resources - since it is the re-visioning and reconstruction of people's identities that is essential in this process. Here the iconic character of the figures has transformed in multiple ways over time. Created as an original idol of worship in Buddhist times it was known to the eastern world as an admired Wonder of Creation in classic Arabic literature. Since then, the local perception of the figures has adopted and integrated the original statues as part of a mythical legend on Salsal, a prince of Bamiyan and Shamana, a princess from another kingdom, who turned into stone, rather than living apart (Inaba 2019). In their fragmentary condition before the destruction, the figures represented all this, and even in their current dilapidated form, the figure fragments express a memorial value of the destruction events the valley had experienced before. Apart from the variety of meanings in the different historical-cultural contexts, the figures and the now empty niches retained an idiosyncratic element, very much bound to the specific place. Therefore, a potential reconstruction project has to be aware of these connotations of the past while allowing for ample interpretations of a future narrative that is not yet told. It is for the sake of the success of the envisioned goal that re-building an important heritage symbol contributes to peace processes, reconciliation, and the rebuilding of society in the widest sense. Therefore digital simulations experienced in immersive VR environments bear the chance to avoid simplistic approaches or misinterpretation of scientific facts, resulting in counterproductive results. Considering the fact that the notion of authenticity is culturally mediated and that it involves complex networks of relationships between people, places, things, and concepts, it is assumed also that digital reconstructions and physical replicas can acquire authenticity depending on their modes of production and consumption, and the networks of institutional and individual relations from which they arise. Taking this into consideration, the rebuilding of figural elements by active involvement of people of Bamiyan using traditional techniques and materials seems to be the only natural course of action in order to preserve the figural remains and to maintain the authenticity and integrity of the monument. The authors are convinced that it is feasible to reproduce the new plaster surfaces as closely as possible to the historic remains by combining 
traditional techniques and advances restoration science approaches. The continuous monitoring, observation, and evaluation of works, damage, and decay processes is regarded essential and will result in a long-year international assistance project for the long-term preservation of this important WH site.

\section{References}

Ambraseys, N., \& Bilham, R. (2014). The tectonic setting of Bamiyan and seismicity in and near Afghanistan for the past twelve centuries. In C. Margottini (Ed.), After the destruction of giant Buddha statues in Bamiyan (Afghanistan) in 2001 (pp. 101-152). Berlin/Heidelberg: Springer.

Blaensdorf, C., Pfeffer, S., \& Melzl, E. (2009). The polychromy of the giant Buddha statues in Bamiyan. In M. Petzet (Ed.), The giant Buddhas of Bamiyan. safeguarding the remains (pp. 237-264). Berlin: Bäßler.

Bourrouilh-Le Jan, F. G., Akram, B., \& Schvoerer, M. (2007). Band-e-Amir Lakes and Dragon Valley (Bamiyan): Myths and seismicity in Afghanistan. Geological Society London Special Publications, 273, 121-132. https://doi.org/10.1144/GSL.SP.2007.273.01.11.

Delmonaco, G., \& Margottini, C. (2014). General environmental condition of the Bamiyan Valley. In C. Margottini (Ed.), After the destruction of giant Buddha statues in Bamiyan (Afghanistan) in 2001: A UNESCO's emergency activity for the recovering and rehabilitation of cliff and niches (pp. 69-100). New York: Springer.

Emmerling, E., \& Petzet, M. (Eds.). (2016). The giant Buddhas of Bamiyan II. Safeguarding the remains 2010-2015, Berlin: Bäßler.

Fecker, E. (2009). Report on rock mechanical aspects concerning the Eastern Buddha Niche, 2006. In M. Petzet (Ed.), The giant Buddhas of Bamiyan. Safeguarding the remains (pp. 103-116). Berlin: Bäßler.

Higuchi, T. (1984). Bamiyan. Art and Archaeological researches on the Buddhist cave temples in Afghanistan 1970-78. Dohosha.

ICOMOS. (2017). ICOMOS guidance on post-trauma recovery and reconstruction for World Heritage Cultural Properties.

ICOMOS. (2016). Report of the ICOMOS Advisory Mission to cultural landscape and archaeological remains of the Bamiyan Valley (26-31 May 2014). In E. Emmerling \& M. Petzet (Eds.), The giant Buddhas of Bamiyan II. Safeguarding the remains 2010-2015 (pp. 245-269). Berlin: Hendrik Bäßler Verlag.

Inaba, M. (2019). The narratives on the Bāmiyān Buddhist remains in the Islamic period. In Blain Auer and Ingo Strauch, (Eds.) encountering Buddhism and Islam in Premodern central and South Asia (pp. 75-96). Berlin, Boston: De Gruyter.

Jansen, M., Toubekis, G., Walther, A., Döring-Williams, M., \& Mayer, I. (2008). Laser scan measurement of the niche and virtual 3D representation of the Small Buddha in Bamiyan. In A. Posluschny, K. Lambers, \& I. Herzog (Eds.), Layers of perception: Proceedings of the 35th International Conference on Computer Applications and Quantitative Methods in Archaeology (CAA), Berlin, Germany, April 2-6, 2007 (pp. 83-90). Bonn:Habelt. https://doi.org/10.11588/ propylaeumdok.00000531

Lang, J. (1972). Bassins intramontagneux néogènes de l'Afghanistan Central. Revue de Geographie Physique et de Geologie Dynamique, 14, 415-427.

Lang, J. (1968). La serie neogene de Bamian (Afghanistan). Comptes Rendus Académie Sci, 266, 2383-2384.

Larsen, K. E. (Ed.). (1995). Proceedings of the Nara Conference on Authenticity in Relation to the World Heritage Convention: Nara, Japan, 1-6 November $1994=$ Comte-Rendu. Paris: UNESCO World Heritage Centre [u.a.]. 
Margottini, C. (Ed.). (2014a). After the destruction of giant Buddha statues in Bamiyan (Afghanistan) in 2001: A UNESCO's emergency activity for the recovering and rehabilitation of cliff and niches. New York: Springer.

Margottini, C. (Ed.). (2014b). Properties of local material. In: After the destruction of Giant Buddha statues in Bamiyan (Afghanistan) in 2001: A UNESCO's emergency activity for the recovering and rehabilitation of cliff and niches (pp. 153-171). New York: Springer.

Mitchell, N. J., Rössler, M., \& Tricaud, P.-M. (Eds.). (2009). World heritage cultural landscapes: A handbook for conservation and management (World Heritage paper series). Paris: UNESCO World Heritage Centre.

Petzet, M. (Ed.). (2009). The Giant Buddhas of Bamiyan. Safeguarding the remains, Monuments and Sites Volume 19. Berlin: Bäßler.

Reinecke, T. (2005). Environmental Assessment of the Bamiyan Valley in the Central Highlands of Afghanistan - Bamiyan Master Plan campaign 2005 (Field Report). Aachen: Aachen Center for Documentation and Conservation.

Schmidt, H. (1997). Reconstruction of ancient buildings. In M. de la Torre (Ed.), The Conservation of Archaeological Sites in the Mediterranean Region: An International Conference Organized by the Getty Conservation Institute and the J. Paul Getty Museum, 6-12 May 1995 (pp. 41-50). Los Angeles:Getty Conservation Institute. https://www.getty.edu/conservation/publications_resources/pdf_publications/conserv_sites_mediterranean.html

Taniguchi, Y. (2013). Conserving the Buddhist Wall paintings of Bamiyan in Afghanistan: Practical issues and dilemmas. In D. Park, D. Wangmo, \& S. Cather (Eds.), Art of merit: Studies in Buddhist art and its conservation (pp. 124-139). London: Archetype Publications.

Tarzi, Z. (1977). L'architecture et le décor rupestre des grottes de Bāmiyān. Paris: Impr. Nationale.

Toubekis, G. (2008). Kleiner Buddha-Dokumentation Fragmente (Fieldwork July-October 2006). In G.Toubekis \& M. Jansen, ICOMOS Project Afghanistan. Preservation of the Buddha Fragments in Bamiyan. Reports 2006-2007-2008. RWTH Aachen University:Aachen Center for Documentation and Conservation.

Toubekis, G., Jansen, M., \& Jarke, M. (2017). Long-term preservation of the physical remains of the destroyed Buddha figures in Bamiyan (Afghanistan) using virtual reality technologies for preparation and evaluation of restoration measures. ISPRS Annals of the Photogrammetry, Remote Sensing and Spatial Information Sciences, IV-2/W2, 271-278. https://doi.org/10.5194/ isprs-annals-IV-2-W2-271-2017.

Toubekis, G., Mayer, I., Döring-Williams, M., Maeda, K., Yamauchi, K., Taniguchi, Y., Morimoto, S., Petzet, M., Jarke, M., \& Jansen, M. (2011). Preservation and management of the UNESCO World Heritage Site of Bamiyan: Laser SCAN documentation and virtual reconstruction of the destroyed Buddha figures and the archaeological remains. In E. Stylianidis, P. Patias, \& M. Q. Santana (Eds.), CIPA Heritage documentation: Best practise and applications, Series 1, $2007 \& 2009$ (pp. 93-100). DOI: 10.18154/RWTH-CONV-185618

Urbat, M. (2009). A combined geological and Paleomagnetic approach towards the repositioning of fragments from the Buddha Statues (Report 2006). In M. Petzet (Ed.). The Giant Buddhas of Bamiyan - Safeguarding the Remains (pp. 89-102). Berlin: Bäßler 
The opinions expressed in this chapter are those of the author(s) and do not necessarily reflect the views of the UNESCO, its Board of Directors, or the countries they represent.

Open Access This chapter is licensed under the terms of the Creative Commons AttributionShareAlike 3.0 IGO License (https://creativecommons.org/licenses/by-sa/3.0/igo/), which permits use, sharing, adaptation, distribution, and reproduction in any medium or format, as long as you give appropriate credit to UNESCO, provide a link to the Creative Commons licence and indicate if changes were made. If you remix, transform, or build upon this chapter or a part thereof, you must distribute your contributions under the same licence as the original. This publication is also available at the UNESCO Open Access Repository: https://unesdoc.unesco.org/

The designations employed and the presentation of material throughout this publication do not imply the expression of any opinion whatsoever on the part of UNESCO concerning the legal status of any country, territory, city or area or of its authorities, or the delimitation of its frontiers or boundaries.

The authors are responsible for the choice and the presentation of the facts contained in this chapter and for the opinions expressed therein, which are not necessarily those of UNESCO and do not commit the Organization.

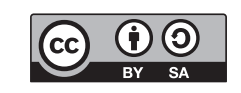

